\title{
PENGEMBANGAN ALAT CONTROL CHARGING PANEL SURYA MENGGUNAKAN ADUINO NANO UNTUK SEPEDA LISTRIK NIAGA
}

\author{
Kurnifan Adhi Prasetyo ${ }^{1}$, Nurhening Yuniarti ${ }^{2}$, Eko Prianto ${ }^{3}$ \\ ${ }^{1}$ Mahasiswa Jurusan Pendidikan Teknik Elektro FT UNY \\ ${ }^{2,3}$ Dosen Jurusan Pendidikan Teknik Elektro FT UNY \\ Email: kurnifan@gmail.ac.id
}

\begin{abstract}
The purpose of this research is to know the stages of manufacture, the performance and the development of solar panel control charging devices using arduino nano for commercial electric bicycle. Development of solar panel control charging device is expected to be used in utilizing solar thermal energy as a source of energy on a commercial electric bike with parameters generated from solar panels and battery charging. The result of this research is a solar panel charging control device that is used to control the input voltage from the solar panel to the battery used as a power source for the electric bicycle. The result are, the average battery charging power using 100 Watt Peak (WP) solar panel was 39.03 Watt with 160 minutes, the average efficiency of $85.82 \%$ and the yield of the battery voltage from $11 \mathrm{Vdc}$ to $12.5 \mathrm{Vdc}$. While the average power charging battery using 300 WP solar panel is 57,43 Watt with time 50 minutes, average efficiency of $88.48 \%$ and battery voltage from $11 \mathrm{Vdc}$ become 12,2 Vdc. Average percentage error of measurement parameter control charging solar panels below $10 \%$.
\end{abstract}

Keywords: control charging, solar panels, electric bike

\begin{abstract}
ABSTRAK
Tujuan dari penelitian ini adalah untuk mengetahui tahapan pembuatan, unjuk kerja dari pengembangan alat control charging panel surya menggunakan arduino nano untuk sepeda listrik niaga. Pengembangan alat control charging panel surya ini diharapkan dapat digunakan dalam memanfaatkan energi panas matahari sebagai sumber energi pada sepeda listrik niaga dengan parameter parameter yang dihasilkan dari panel surya dan pengisian aki. Hasil dari pembuatan proyek akhir ini berupa alat control charging panel surya yang digunakan untuk mengontrol tegangan masukan dari panel surya menuju aki yang dimanfaatkan sebagai sumber tenaga sepeda listrik niaga. Hasil pengujian, daya rata rata pengisian aki menggunakan panel surya $100 \mathrm{Watt}$ Peak (WP) yang diuji adalah 39,03 Watt dengan waktu 160 menit, rata-rata efisiensi 85,82\% dan hasil tegangan aki dari $11 \mathrm{Vdc}$ menjadi 12,5 Vdc. Sedangkan daya rata rata pengisian aki menggunakan panel surya $300 \mathrm{WP}$ yang diuji adalah 57,43 Watt dengan waktu 50 menit, rata-rata efisiensi $88.48 \%$ dan tegangan aki dari $11 \mathrm{Vdc}$ menjadi 12,2 Vdc. Rata-rata persentase kesalahan parameter pengukuran alat control charging panel surya dibawah $10 \%$.
\end{abstract}

Kata Kunci : control charging, panel surya, Sepeda Listrik Niaga

\section{PENDAHULUAN}

Penggunaan energi listrik semakin bertambah seiring dengan perkembangan teknologi. Padahal sumber daya alam saat ini semakin berkurang, sedangkan penggunaan energi listrik bahan bakar fosil dalam jangka panjang akan menguras sumber daya alam. Dalam kasus ini, perlu mengembangkan energi alternatif yang dihasilkan dari sumber daya alam yang melimpah. Pemanfaatan energi terbarukan yang lebih ramah lingkungan perlu dioptimalkan, Indonesia memiliki sumber daya Enegi baru terbarukan (EBT) yang lengkap dari langit, bumi, hingga air, sehingga dapat segera menjadi EBT yang utama. Pemanfaatan energi terbarukan is a must, tidak lagi sekedar 
alternatif tetapi harus menjadi mainstream. (Rida Mulyana, 2017:9).

Salah satu EBT yaitu Pembangkit Listrik Tenaga Surya (PLTS). PLTS saat ini sudah banyak dikembangkan di berbagai tempat di Indonesia. Salah satu pemanfaatannya adalah sebagai penyuplai energi pada alat transportasi ramah lingkungan seperti Sepeda Listrik Niaga Fakultas Teknik Universitas Negeri Yogyakarta. Sepeda Listrik Niaga menggunakan motor listrik arus searah sebagai penggerak utama yang disuplai dari baterai sebagai media penyimpanan listrik arus searah.

Alat yang dibutuhkan untuk mengalirkan energi surya diantaranya adalah panel surya, solar charger controller, dan baterai aki sebagai media penyimpanan energi listrik. Ketika intensitas cahaya matahari lemah, alat control charging masih kurang optimal untuk menyalurkan energi listrik menuju baterai. Sehingga energi listrik yang masuk ke Aki mengalami penurunan dan menimbulkan proses membutuhkan waktu lebih lama.

Pembacaan parameter pengukuran nilai Arus, Tegangan, dan Daya pada saat pengisian energi listrik masih dengan cara manual menggunakan alat ukur. Sehingga ketika akan melakukan pengukuran parameter pengisian energi litrik menuju aki harus menyiapkan dan memasang alat ukur terlebih dahulu. Pengukuran parameter pengisian energi listrik dengan alat ukur manual kurang efektif karena membutuhkan waktu saat pengisian energi listrik menuju aki berpindah tempat atau tidak tergabung menjadi satu dengan alat control charging panel surya.

Berdasarkan permasalahan tersebut perlu dirancang pengembangan control charging panel surya yang lebih optimal. Pengembangan control charging panel surya ini dirancang menyesuaikan perkembangan teknologi saat ini yaitu memanfaatkan teknologi berbasis mikrokontroler. Pengembangan control charging panel surya merupakan alat yang dibutuhkan pada PLTS untuk mengontrol masuknya arus pengisian menuju baterai ditambah dengan pembacaan parameter pengukuran Arus, Tegangan, dan Daya saat pengisian energi listrik menuju baterai yang ditampilkan dalam layar $L C D$.

\section{METODE}

Control Charging Panel Surya merupakan rangkaian elektronik yang mengatur proses pengisian baterai atau rangkaian aki (Battery Bank) dari panel surya. Tegangan DC yang dihasilkan oleh panel sel surya umumnya bervariasi 12 volt ke-atas. Kontroler ini berfungsi sebagai alat pengatur tegangan baterai agar tidak melampaui batas. Disamping itu, alat pengontrol ini juga mencegah pengaliran arus dari baterai mengalir balik ke panel sel surya ketika proses pengisian sedang tidak berlangsung (misalnya pada malam hari) sehingga baterai yang sudah diisi tidak terkuras tenaganya. Apabila baterai atau rangkaian aki sudah penuh terisi, maka aliran DC dari panel surya akan diputuskan agar baterai itu tidak lagi menjalani pengisian sehingga pengerusakan terhadap baterai bisa dicegah dan usia aki bisa diperpanjang. Pengendalian proses pengisian baterai dengan membuka dan menutup aliran arus DC dari panel surya ke baterai adalah fungsi yang paling dasar sebuah charge controller.

Pengembangan alat control charging panel surya dirancang dengan perkembangan teknologi saat ini untuk memaksimalkan daya listrik yang dihasilkan dari panel surya dengan mencari nilai titik maksimum. Pengembangan lain adalah pembacaan parameter pengukuran kontrol pengisian energi listrik dari panel surya menuju baterai. Pembacaan parameter pengukuran biasanya dilakukan dengan cara manual dapat dibuat lebih praktis dengan menampilkan parameter pengukuran daya, tegangan, arus saat pengisian energi listrik, sehingga parameter pengukran dapat ditampilkan dalam LCD. 
Komponen utama dan pendukung yang digunakan dalam penelitian ini yaitu Arduino, Unit Penurun Tegangan DC ke DC, Sensor Arus, Sensor Tegangan, Liquid Cristal Display (LCD), Panel Surya, Baterai Aki dan Sepeda Listrik Niaga. Arduino yang merupakan sebuah platform hardware yang bersifat open-source. Papan Arduino yang digunakan adalah ATMEGA328. Program yang di gunakan Arduino adalah bahasa pemerograman yang dimiliki oleh Arduino sendiri, namun memiliki kemiripan syntax dengan bahasa pemrograman C. Modul regulator penurun tegangan dalam Unit Penurun Tegangan DC ke DC mengunakan bahan solid capacitor dan PCB berkualitas untuk menjamin kualitas tegangan yang dibutuhkan. Sensor arus yang digunakan adalah sensor arus ACS712 (Allegroo Current Sensor). ACS 712 berfungsi untuk mendeteksi besaran arus yang mengalir lewat blok terminal. Sensor tegangan berfungsi sebagai sensor pembanding antara tegangan yang diukur dengan tegangan tegangan maksimal yang diijinkan untuk diolah pada mikrokontroler. LCD yang digunakan pada alat pengukuran parameter control charging panel surya ini mengguakan LCD 20x4. LCD 20x4 merupakan LCD yang terdiri dari 4 baris dan 20 karakter.

$$
\text { Panel Surya adalah teknologi }
$$
berdasarkan semikonduktor dalam kondisi padat yang mengkonversi energi cahaya matahari secara langsung menjadi energi listrik, tanpa ada bagian yang berputar, tidak menimbulkan kebisingan, dan tanpa mengeluarkan gas buangan. Akumulator yang digunakan untuk sistem pembangkit listrik tenaga surya mempunyai fungsi ganda. Pada suatu sisi akumulator memilki fungsi sebagai penyimpan energi, sedangkan disisi lain baterai berfungsi sebagai catu daya beban. Pada penyimpanan ini menggunakan Aki dengan input tegangan 12-16 Vdc dengan kemampuan 12 Ah. Motor listrik DC digunakan sebagai penggerak Sepeda Listrik Niaga karena menggunakan arus listrik searah dalam sistemnya. Motor listrik yang digunakan adalah motor BLDC 48 V 500 watt. Karena tegangan kerja motor BLDC yaitu $48 \mathrm{~V}$ dan juga mempertimbangkan faktor ekonomis serta fleksibilitas, maka baterai Aki yang digunakan adalah baterai $12 \mathrm{~V}$ yang dirangkai secara seri sebanyak 4 buah sehingga tegangan total baterai menjadi $48 \mathrm{~V}$ sesuai dengan beban motor BLDC.

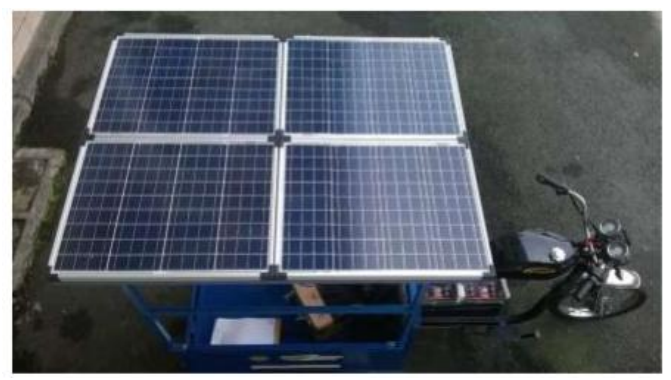

Gambar 1. Sepeda Listrik Niaga FT UNY

Konsep rancangan pembuatan pengembangan alat control charging panel surya secara keseluruhan melalui 4 tahapan: (1) analisis kebutuhan alat dan bahan ; (2) tahap perancangan alat; (3) tahap pembuatan alat; dan (4) tahap pengujian. Analisis kebutuhan alat dan bahan dilakukan untuk mengidentifikasi peralatan-peralatan dan sarana bahan untuk menunjang dalam pembuatan alat dan pemantauan data.

Tahap perancangan merupakan tahapan untuk merancang rangkaian yang dibutuhkan dalam pembuatan pengembangan alat control charging panel surya. Proses perancangan dan pembuatan pengembangan alat control charging panel surya ini melalui beberapa tahap.

Perancangan rangkaian elektronika menggunakan software Proteus untuk melakukan simulasi. Langkah awal merancang rangkaian elektronika yaitu membuat blok diagram dari sistem yang akan dibuat seperti yang ditunjukkan oleh gambar 2 . 


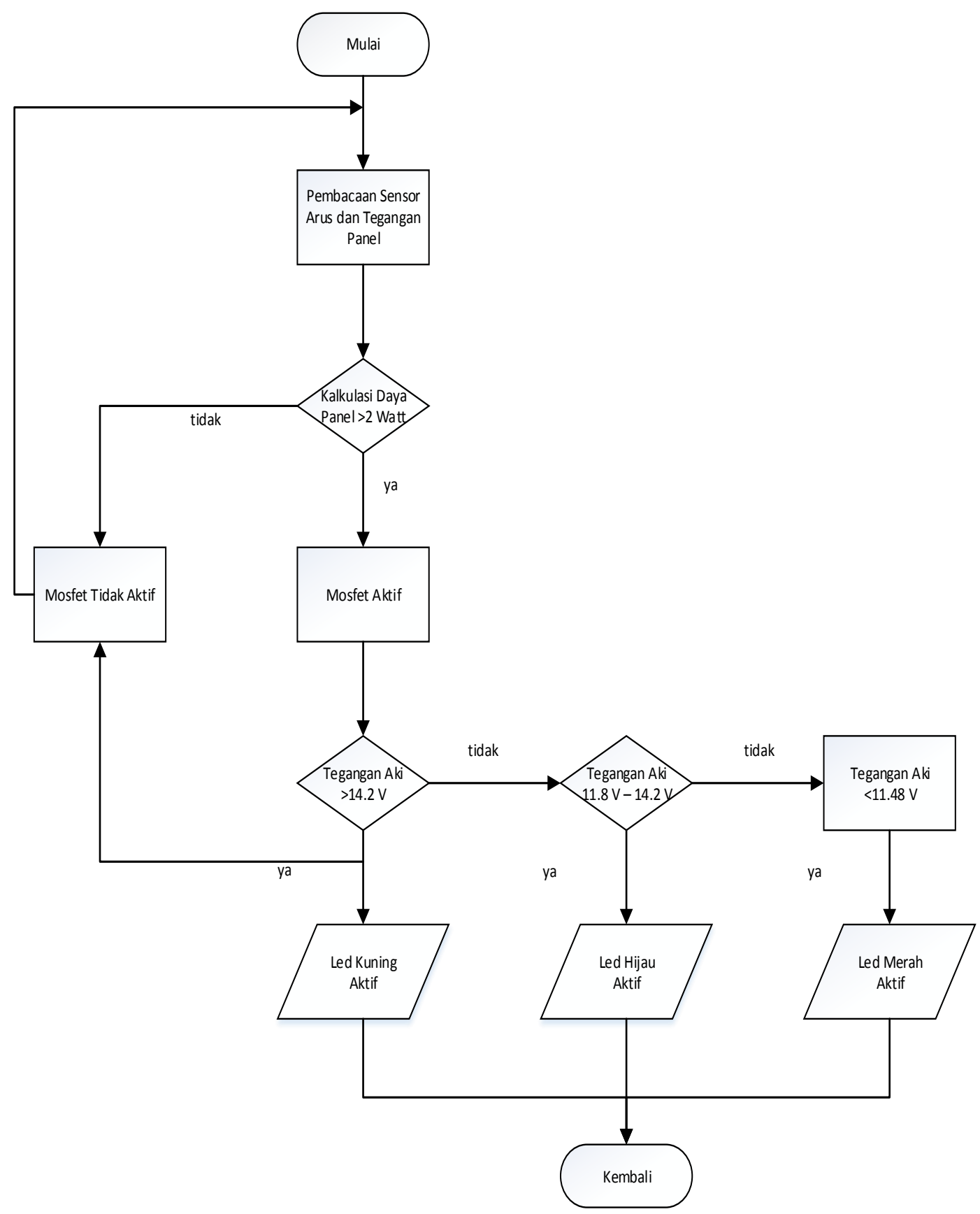

Gambar 2. Flowchart Alat Control Charging Panel Surya

Catu daya untuk alat pengembangan sistem charging controller panel surya menggunakan modul regulator penurun tegangan. Prinsip kerja regulator penurun tegangan ini adalah menurunan sumber tegangan DC dari baterai aki antara $11 \mathrm{Vdc}-$ $13 \mathrm{Vdc}$ menjadi $5 \mathrm{Vdc}$ sesuai dengan kebutuhan arduino nano. 


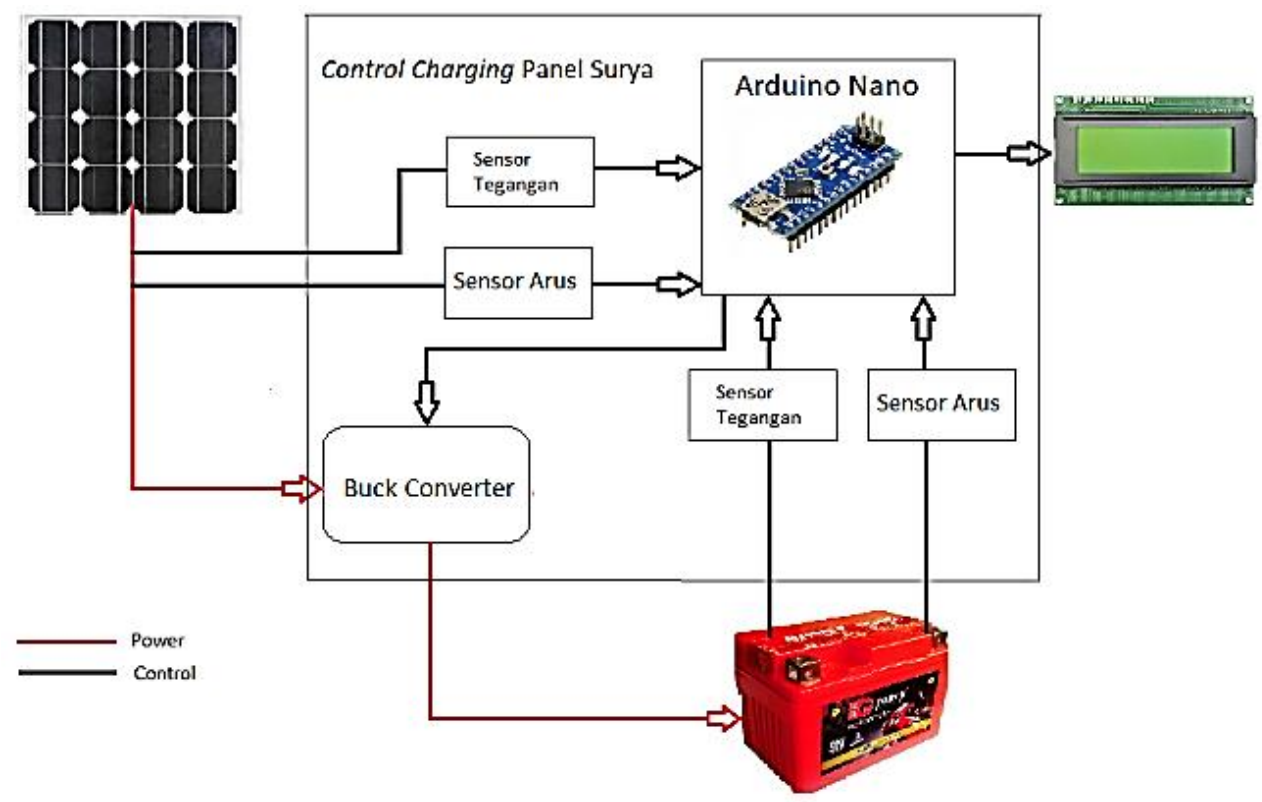

Gambar 3. Skema Rancangan Alat

Perancangan sensor tegangan dalam alat control charging berfungsi sebagai data masukan yang akan diolah dipadukan dengan sensor arus yang menghasilkan daya dari panel surya sebagai parameter untuk mengkatifkan mosfet. Rangkaian sensor tegangan ini bekerja dengan menurunkan level tegangan dari tegangan yang diukur menjadi tegangan yang diijinkan arduino.

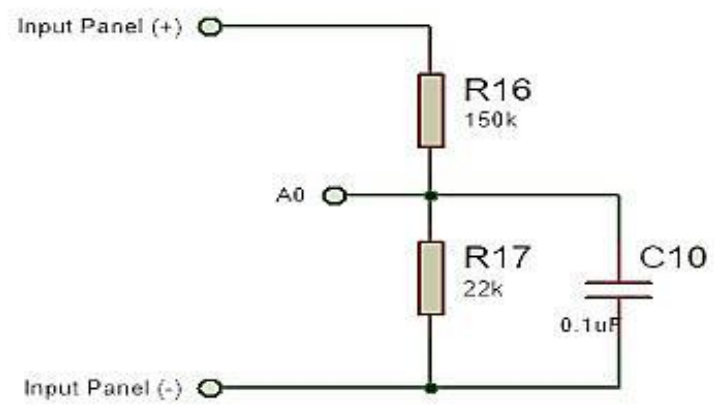

Gambar 4. Rangkaian Sensor Tegangan

Perancangan sensor arus dalam alat control charging panel surya berfungsi sebagai data masukan yang akan diolah dipadukan dengan sensor tegangan yang menghasilkan daya dari panel surya sebagai parameter untuk mengkatifkan mosfet. Sensor arus yang digunakan adalah modul sensor arus ACS 712 30A.

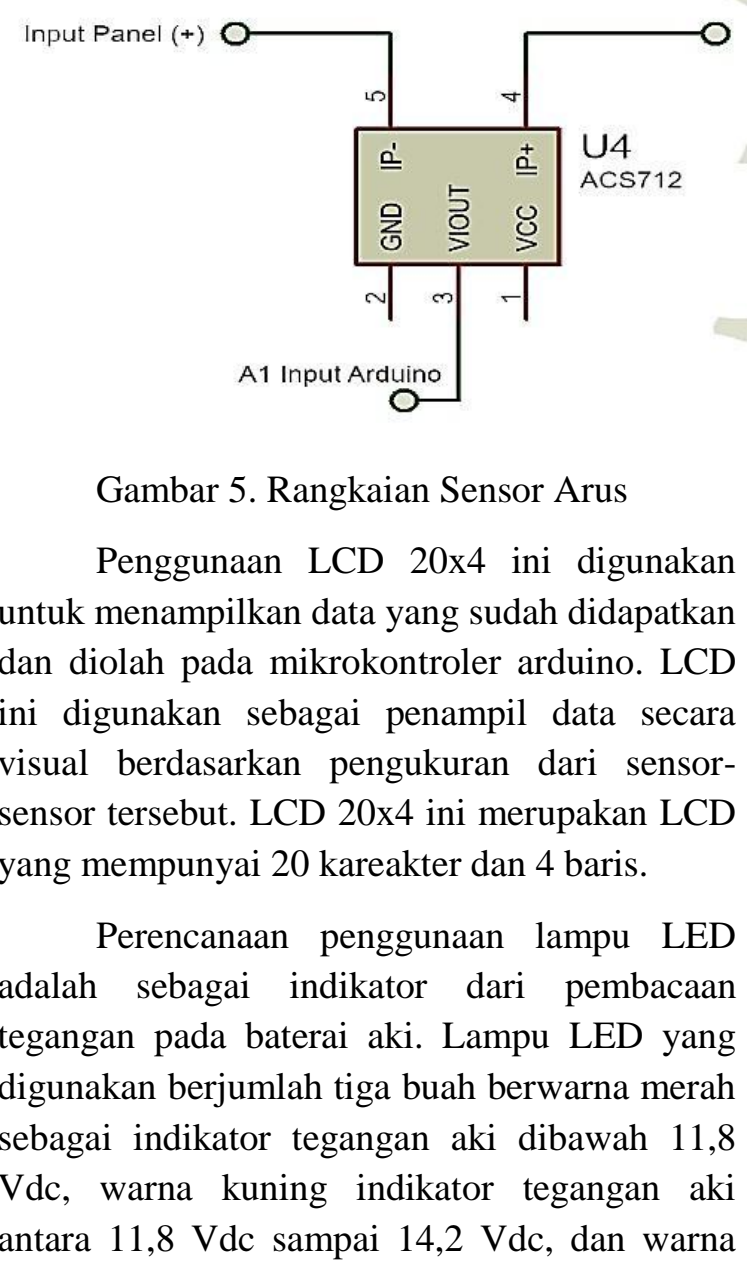


hijau sebagai indikator tegangan melebihi 14,2 Vdc.

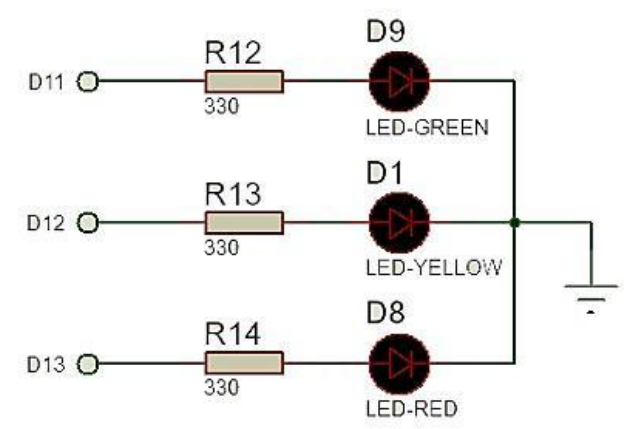

\section{Gambar 6. Rangkain LED}

Perancangan penggunaan mosfet IRFZ44N adalah sebagai saklar elektronik yang dikendalikan dari driver mosfet IR2104 dimana driver mosfet mendapat masukan dari hasil pembacaan sensor arus dan sensor tegangan arduino nano. Mosfet akan aktif jika daya hasil perkalian dari pembacaan arus dan tegangan panel telah memenuhi syarat. Mosfet akan menjadi nonaktif ketika daya panel dan tegangan pengisian baterai aki tidak sesuai dari persyaratan.

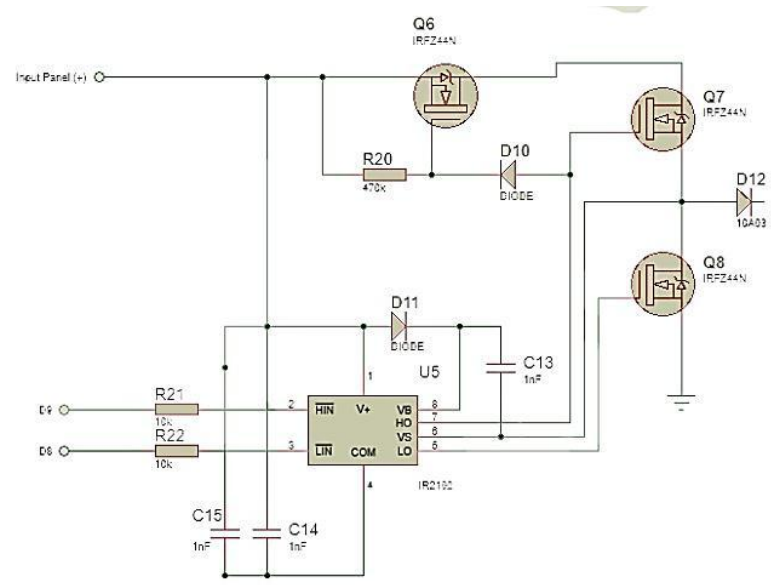

Gambar 7. Rangkaian Mosfet Sebagai Saklar

Penggunaan rangkaian buck converter adalah untuk menurunkan tegangan dari panel surya menuju baterai aki. Tegangan dari panel surya yang mencapai $17 \mathrm{Vdc}$ saat pengisian dapat mengurangi usia dari baterai aki akibat tegangan masukan yang berlebihan.

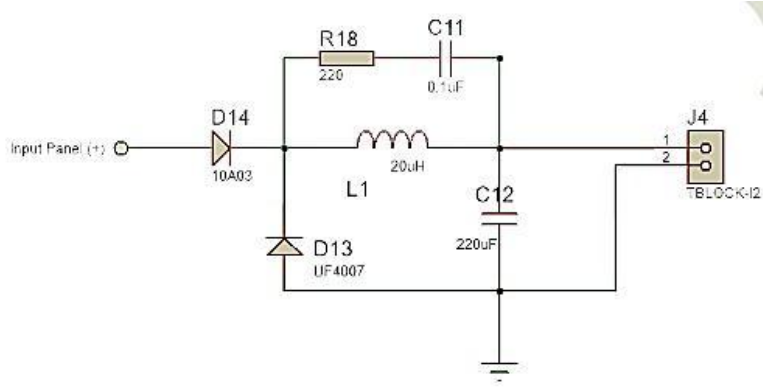

Gambar 8. Rangkaian Buck Converter

Tahap pembuatan dilaksanakan untuk merealisasikan alat control charging panel surya setelah dilakukan perancanaan alat control charging panel surya. Tahap pembuatan ini meliputi pencetakan gambar rangkaian, pelarutan PCB, pengeboran PCB, pemasangan komponen, dan permrograman rangkaian.

\section{HASIL DAN PEMBAHASAN}

Pengujian alat control charging panel surya merupakan proses yang dilakukan untuk mengetahui kemampuan dan unjuk kerja dari kondisi alat. Selain itu pengujian ini dilakukan untuk mengetahui tingkat kesesuaian alat control charging panel surya dalam pengukuran parameter-parameter pada pembangkit listrik tenaga surya.

Tabel 1. Pengujian Sensor Tegangan Panel Surya

\begin{tabular}{ccc}
\hline No. & $\begin{array}{c}\text { Tegangan } \\
\text { Masukan } \\
(\mathrm{V})\end{array}$ & $\begin{array}{c}\text { Tegangan Keluaran } \\
(\mathrm{V})\end{array}$ \\
\hline 1. & 0 & 0 \\
\hline 2. & 1,5 & 0,2 \\
\hline 3. & 3 & 0,35 \\
\hline 4. & 11,7 & 1,3 \\
\hline 5. & 15,5 & 1,7 \\
\hline 6. & 19 & 2,1 \\
\hline
\end{tabular}


Tabel 2. Pengujian Sensor Tegangan Aki

\begin{tabular}{ccc}
\hline No. & $\begin{array}{c}\text { Tegangan Masukan } \\
(\mathrm{V})\end{array}$ & $\begin{array}{c}\text { Tegangan } \\
\text { Keluaran } \\
(\mathrm{V})\end{array}$ \\
\hline 1. & 0 & 0 \\
\hline 2. & 1,5 & 0,25 \\
\hline 3. & 3 & 0.45 \\
\hline 4. & 11,7 & 1,95 \\
\hline 5. & 15,5 & 2,5 \\
\hline 6. & 19 & 3,1 \\
\hline
\end{tabular}

Tabel 3. Pengujian sensor arus panel surya

\begin{tabular}{ccccc}
\hline No. & $\begin{array}{c}\text { Pemberemete } \\
\mathrm{r} \\
\text { (A) }\end{array}$ & $\begin{array}{c}\text { Pembaca } \\
\text { an Sensor } \\
\text { Arus } \\
\text { (A) }\end{array}$ & $\begin{array}{c}\text { Selisi } \\
\mathrm{h}\end{array}$ & $\begin{array}{c}\text { Persenta } \\
\text { se } \\
\text { Selisih } \\
(\%)\end{array}$ \\
\hline 1. & 0 & 0,02 & 0,02 & $0 \%$ \\
\hline 2. & 0,7 & 0,72 & 0,02 & $2,86 \%$ \\
\hline 3. & 1,6 & 1,72 & 0,12 & $7,50 \%$ \\
\hline 4. & 2,4 & 2,58 & 0,18 & $7,50 \%$ \\
\hline 5. & 4,6 & 4,45 & 0,25 & $5,43 \%$ \\
\hline 6. & 4,8 & 5,23 & 0,43 & $8,96 \%$
\end{tabular}

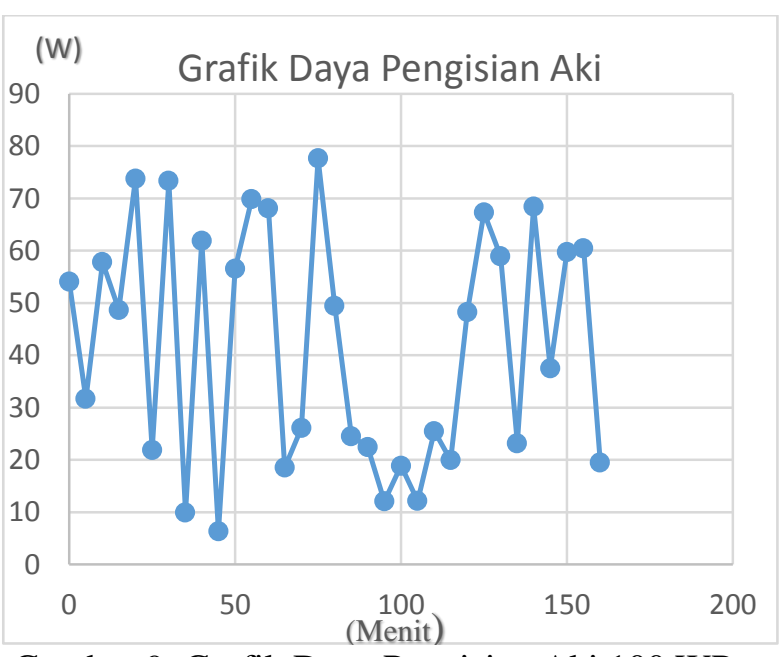

Gambar 9. Grafik Daya Pengisian Aki 100 WP

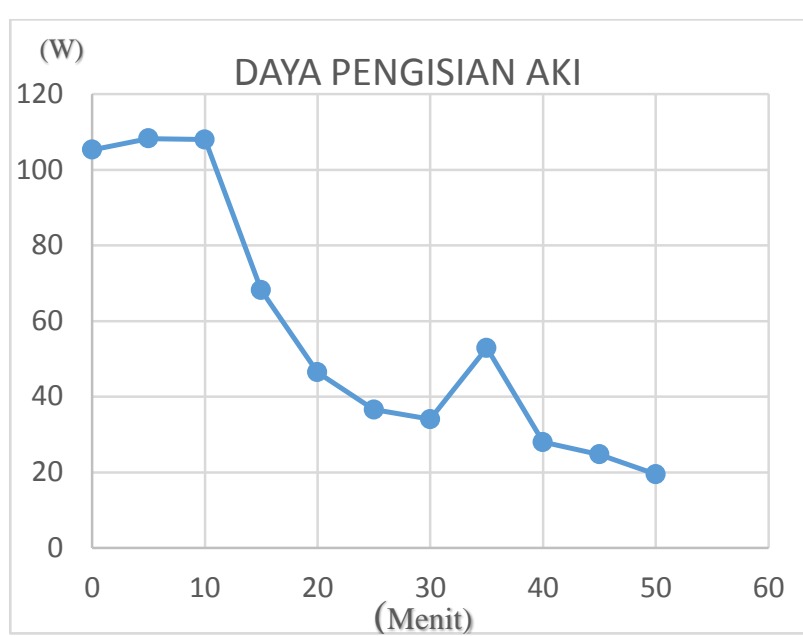

Gambar 20. Grafik Daya Pengisian Aki 300 WP

\section{Pembahasan}

Pengujian alat control charging panel surya diperlukan untuk mengetahui unjuk kerja alat ini. Berdasarkan pengujian yang ditunjukkan Tabel 1 dan Tabel 2 bahwa pengujian sensor tegangan panel surya dengan input tegangan $19 \mathrm{Vdc}$, sensor tegangan menghasilkan output 2,1 Vdc, sedangkan sensor tegangan untuk Aki menghasilkan output 3,1 Vdc. Data tersebut membuktikan bahwa sensor tegangan ini bekerja dengan baik karena dengan pemberian tegangan input $19 \mathrm{Vdc}$ maka sensor tegangan ini dapat mendeteksi penurunan tegangan menjadi 2,1 Vdc untuk sensor tegangan panel surya dan mendeteksi penurunan tegangan menjadi 3,1 Vdc untuk sensor tegangan aki. Tegangan 2,1 Vdc ini akan diolah oleh mikokontroler dan dihitung dengan perbandingan 1:9 hasil dari perbabandingan antara tegangan keluaran 2,1 $\mathrm{Vdc}$ dengan tegangan masukan $19 \mathrm{Vdc}$. Sedangkan tegangan 3,1 Vdc ini akan diolah mikrokontroler dan dihitung dengan perbandingan 1:6 hasil dari perbabandingan antara tegangan keluaran 3,1 Vdc dengan tegangan masukan $19 \mathrm{Vdc}$.

Berdasarkan pengujian tabel 3, semakin besar pengukuran arus, maka semakin besar pula selisih pembacaan sensor arus. Dari pengujian yang ada maka dapat dihitung rata rata persentase kesalahan sebagai berikut: 
Sensor Arus Panel surya:

Rata-rata kesalahan

$$
\begin{aligned}
& =\frac{\text { Jumlah Persentase Kesalahan }}{\text { Jumlah data }} \% \\
& =\frac{32,25}{6} \% \\
& =5,38 \%
\end{aligned}
$$

Sensor Arus Pengisian Aki:

$$
\begin{aligned}
\text { Rata-rata kesalahan } & =\frac{33,89}{6} \% \\
& =5,65 \%
\end{aligned}
$$

Pembahasan unjuk kerja Panel surya 100 WP Rata-rata daya pengisian aki

$$
\begin{aligned}
& =\frac{\text { Jumlah Daya }}{\text { Jumlah data }} \mathrm{W} \\
& =\frac{1288,13}{33} \mathrm{~W} \\
& =39,03 \mathrm{~W}
\end{aligned}
$$

Rata-rata Efisiensi

$$
\begin{aligned}
& =\frac{\text { Rata-rata daya pengisian aki }}{\text { Rata-rata daya panel surya }} \times 100 \% \\
& =\frac{45,48 \mathrm{~W}}{39,03 \mathrm{~W}} \times 100 \% \\
& =85,82 \%
\end{aligned}
$$

Pembahasan unjuk kerja Panel surya 300 WP Rata-rata daya pengisian aki

$$
\begin{aligned}
& =\frac{\text { Jumlah Daya }}{\text { Jumlah data }} \mathrm{W} \\
& =\frac{631,68}{11} \mathrm{~W} \\
& =57,43 \mathrm{~W}
\end{aligned}
$$

Rata-rata Efisiensi

$$
\begin{aligned}
& =\frac{\text { Rata-rata daya pengisian aki }}{\text { Rata-rata daya panel surya }} \times 100 \% \\
& =\frac{57,43 \mathrm{~W}}{64,90 \mathrm{~W}} \times 100 \% \\
& =88,48 \%
\end{aligned}
$$

Pengujian alat control charging Panel Surya menghasilkan data uji pengisian yang sangat baik. Grafik pengisian energi dari panel surya sesuai dengan naik turunnya intensitas cahaya matahari. Persentase kesalahan dari pembacaan nilai Arus, Tegangan, dan Daya masih dibawah toleransi $10 \%$. Untuk memaksimalkan pembacaan paramater nilai pengisian energi listrik menuju listrik DC dapat dimaksimalkan dengan memperbaiki pogram pembacaan adc sehingga pembacaan nilai paramater lebih presisi. Dalam Perbaikan desain box, dapat menggunakan bahan akrilik atau box yang lebih kokoh agar alat lebih kuat digunakan ketika sepeda listrik niaga dioperasikan. Untuk mengantisipasi tegangan lebih atau overvoltage alat control charging dapat ditambah dengan buzzer.

\section{SIMPULAN}

Alat control charging panel surya dirancang dengan tahapan, yaitu: (a) tahap analisis kebutuhan, (b) tahap perancangan komponen yang meliputi perancangan pemilihan arduino nano, regulator step down DC-DC, sensor arus, sensor tegangan, dan LCD 20x4, (c) tahap pembuatan alat yang meliputi pembuatan jalur $\mathrm{PCB}$, pemasangan dan perangkaian komponen secara keseluruhan, dan (d) tahap pengujian unjuk kerja alat.

Unjuk kerja dari alat control charging panel surya ini meliputi pengukuran tegangan, arus, dan daya (keluaran panel surya dan pengukuran saat pengisian aki). Daya rata rata pengisian aki menggunakan panel surya 100 WP yang diuji adalah 39,03 Watt dengan waktu 160 menit, rata-rata efisiensi $85,82 \%$, dan hasil tegangan aki dari $11 \mathrm{Vdc}$ menjadi $12,5 \mathrm{Vdc}$. Sedangkan daya rata rata pengisian aki menggunakan panel surya $300 \mathrm{WP}$ adalah 57,43 Watt dengan waktu 50 menit, rata-rata efisiensi $88,48 \%$, dan tegangan aki dari $11 \mathrm{Vdc}$ menjadi 12,2 Vdc. Rata-rata Persentase kesalahan parameter pengukuran alat control charging panel surya dibawah $10 \%$. 


\section{DAFTAR RUJUKAN}

Ali, Muhamad. 2011. Modul Kuliah Teknik Elektronika Daya. Yogyakarta: Jurusan Pendidikan Teknik Elektro FT UNY.

Astra, I Made, Satwiko, dan Sidopekso, 2011. "Studi Rancang Bangun Solar Charge Controller dengan Indikator Arus, Tegangan dan Suhu Berbasis Mikrokontroler ATMega 8535". Spektra: Jurnal Fisika dan Aplikasinya, Vol, XI, 21.

Bortignon, Simone. 2017. Connecting Solar Panels in Parallel. Diakses pada tanggal 29 September 2017, http://www.mpptsolar.com/en/solarpanels-in-parallel.html

Deba. 2014. Arduino Mppt Solar Charge Controller (Version-3.0). Diakses pada tanggal 19 September 2017, http://www.instructables.com/id/ARDUI NO-SOLAR-CHARGE-

CONTROLLER-Version-30/
Fitriandi, Afrizal. 2016. "Rancang Bangun Alat Monitoring Arus dan Tegangan Berbasis Mikrokontroler dengan SMS Gateway”. Electrician, Vol 10, No,2, 1-12.

Jamal, Abid. 2015. Home Made Maximum Power Point Tracking (MPPT) Charge Controller Alternative energy.

Machmud Effendy, Nur Alif Mardiyah, Khusnul Hidayat. 2017. "Implementasi Maximum Power Point Tracking pada Photovoltaic Berbasis P\&O-Fuzzy". JNTETI, Vol. 6, No. 1, Februari 2017.

Sukandarrumidi. 2013. Energi Terbarukan Konsep Dasar Menuju Kemandirian Energi. Yogyakarta: UGM Press.

Yanuar. (2015). Membuat Rangkaian Alat Buck Converter Dan Boost Converter. Diakses pada tanggal 29 November 2017, http://kursuselektronikaku.blogspot.co.id/ 2015/09/membuat-rangkaian-buck-danboost.html 